\title{
Groups Preserving Ordering in Vectors
}

\author{
Karl Goldberg \\ Institute for Basic Standards, National Bureau of Standards, Washington, D.C.
}

(February 16, 1966)

\begin{abstract}
The group of all nonsingular matrices taking the set of ordered 1 by $n$ real vectors onto itself is determined. It is shown to be homomorphic to the symmetric group on $n-1$ letters. A similar result is found for the subset of nonnegative vectors; its group is homomorphic to the symmetric group on $n$ letters.
\end{abstract}

Key Words: Vectors (ordered, nonnegative), matrices (groups of).

Throughout this note (unless otherwise stated) all vectors are 1 by $n$, all matrices are $n$ by $n$, and all have real entries. Lower case Greek letters will denote vectors.

A vector $\alpha=\left(a_{1} a_{2} \ldots a_{n}\right)$ will be called ordered if

$$
a_{1} \geqslant a_{2} \geqslant . . \geqslant a_{n} .
$$

Let $V$ denote the set of all ordered vectors, and $V_{0}$ the subset of nonnegative ones. Our purpose is to describe the groups of nonsingular matrices which take $V$ onto $V$, and $V_{0}$ onto $V_{0}$, respectively.

We will need the following definition:

$$
P_{\pi}(\tau)=\sum_{i=1}^{n} t_{i} E_{i, \pi(i)}
$$

where $\pi$ is an element of the symmetric group $\mathscr{S}_{n}$ (i.e., $\pi$ is a permutation of $1,2, \ldots, n), \tau=\left(t_{1} t_{2} \ldots t_{n}\right)$, and $E_{i, j}$ is the elementary matrix with 1 in the $i, j$ position and 0 elsewhere. In other words, $P_{\pi}(\tau)$ is the permutation matrix corresponding to $\pi$ with the 1 in the $i$ th row replaced by $t_{i}$ for each $1=1,2, \ldots, n$. Our results are

THeOREM 1. Let $\mathrm{M}(\mathrm{V})$ denote the group of all nonsingular matrices $\mathrm{M}$ such that $\mathrm{VM}=\mathrm{V}$ (with a similar definition for $\left.\mathrm{M}\left(\mathrm{V}_{0}\right)\right)$. Then

$$
\begin{aligned}
\mathrm{M}(\mathrm{V})=\left\{\mathrm{K}^{-1} \mathrm{P}_{\pi}(\tau) \mathrm{K}+\gamma^{T} \epsilon: \pi \epsilon \mathscr{S}_{n}, \pi(\mathrm{n})\right. & =\mathrm{n} ; \\
\tau & \left.>0 ; \epsilon \gamma^{\mathrm{T}} \neq-\mathrm{t}_{\mathrm{n}}\right\}
\end{aligned}
$$

$\mathrm{M}\left(\mathrm{V}_{\mathbf{0}}\right)=\left\{\mathrm{K}^{-1} \mathrm{P}_{\pi}(\tau) \mathrm{K}: \pi \epsilon \mathscr{S}_{n} ; \tau>0\right\}$

where $\mathrm{K}$ is the matrix with ones on and below the main diagonal and zeros elsewhere, $\tau=\left(\mathrm{t}_{1} \mathrm{t}_{2} \ldots \mathrm{t}_{n}\right)$, and $\epsilon=\left(\begin{array}{llll}1 & 1\end{array} \ldots\right.$. 1).

Theorem 2. Let $\mathrm{D}(\tau)=\operatorname{diag}\left(\mathrm{t}_{1} \mathrm{t}_{2} \ldots \mathrm{t}_{\mathrm{n}}\right)$ for $\tau$ $=\left(\mathrm{t}_{1} \mathrm{t}_{2} \ldots \mathrm{t}_{\mathrm{n}}\right)$. Define:

$$
\begin{aligned}
\mathrm{N} & =\left\{\mathrm{K}^{-1} \mathrm{D}(\tau) \mathrm{K}+\gamma^{\mathrm{T}} \epsilon: \tau>0 ; \epsilon \gamma^{\mathrm{T}} \neq-\mathrm{t}_{\mathrm{n}}\right\} \\
\mathrm{N}_{0} & =\left\{\mathrm{K}^{-1} \mathrm{D}(\tau) \mathrm{K}: \tau>0\right\}
\end{aligned}
$$

Then $\mathrm{M}(\mathrm{V}) / \mathrm{N} \cong \mathscr{S}_{\mathrm{n}-1}$ and $\mathrm{M}\left(\mathrm{V}_{0}\right) / \mathrm{N}_{0} \cong \mathscr{S}_{\mathrm{n}}$.

We begin with a proof of the results for $V_{0}$. We note that

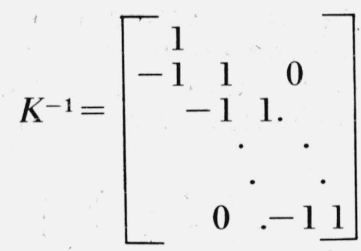

so that

$$
\alpha K^{-1}=\left(a_{1}-a_{2} a_{2}-a_{3} \ldots a_{n-1}-a_{n} a_{n}\right) .
$$

It follows that $\alpha \epsilon V_{0}$ if and only if $\alpha K^{-1} \geqslant 0$.

Let $S$ denote the set of all nonnegative vectors. We have shown that

$$
V_{0} K^{-1}=S
$$

Thus

$$
V_{\mathbf{0}} \boldsymbol{M}=V_{\mathbf{0}} \text { iff } S\left(K M K^{-1}\right)=S .
$$

In other words:

$$
M\left(V_{0}\right)=K^{-1} M(S) K
$$

and our problem is reduced to describing $M(S)$.

By considering those vectors with exactly one 1 and otherwise zero entries, it is easy to see that any matrix which takes all nonnegative vectors into nonnegative vectors is itself nonnegative. To be a member of $M(S)$ both the matrix and its inverse must have that property. But a matrix and its inverse are both nonnegative if and only if it has exactly one positive entry in each row and column, i.e., if it is of the form $P_{\pi}(\tau)$ with $\tau>0$. Thus

$$
M(S)=\left\{P_{\pi}(\tau): \pi \epsilon \mathscr{S}_{n} ; \tau>0\right\} .
$$


Together with (2), this proves our description of $M\left(V_{0}\right)$ in Theorem 1.

Now let $f$ denote the mapping of $M\left(V_{0}\right)$ onto $\mathscr{S}_{n}$ defined by

$$
f\left(K^{-1} P_{\pi}(\tau) K\right)=\pi^{-1} .
$$

This is a homomorphism because

$$
P_{\pi_{1}}(\tau) P_{\pi_{2}}(\sigma)=P_{\pi_{2} \pi_{1}}(\rho)
$$

with $r_{i}=t_{i} s_{\pi_{1}(i)}$ for $i=1,2, \ldots ., n$ (where $\tau=\left(t_{i}\right)$, $\left.\sigma=\left(s_{i}\right), \rho=\left(r_{i}\right)\right)$. The kernel of $f$ is the set of elements $K^{-1} P_{e}(\tau) K$ which are taken into the identity permutation $e$. But $P_{e}(\tau)=D(\tau)$ so that the kernel of $f$ is $N_{0}$. By the first law of homomorphism we conclude that the factor group $M\left(V_{0}\right) / N_{0}$ is isomorphic to $\mathscr{S}_{n}$.

The case for $V$ is slightly different. From (1) we see that $\alpha \epsilon V$ if and only if the first $n-1$ entries of $\alpha K^{-1}$ are nonnegative. Let $S^{*}$ be the set of such vectors. As before we get

$$
M(V)=K^{-1} M\left(S^{*}\right) K .
$$

By considering the vectors $\left(\begin{array}{llll}0 & 0 & \ldots & 0 \pm 1\end{array}\right)$ and those with exactly one 1 in the first $n-1$ positions and zeros elsewhere, we see that a matrix taking all elements of $S^{*}$ into elements of $S^{*}$ must have the form

$$
A=\left(\begin{array}{l|l}
A_{0} & \beta_{0}^{T} \\
\hline 0 & d
\end{array}\right)
$$

where $A_{0}$ is a nonnegative matrix of order $n-1$.

For $A$ to be a member of $M\left(S^{*}\right)$ its inverse must be of the same form. We have

$$
A^{-1}=\left(\begin{array}{c|c}
A_{0}^{-1} & \gamma_{0}^{T} \\
\hline 0 & d^{-1}
\end{array}\right), \quad \gamma_{0}^{T}=-d^{-1} A_{0}^{-1} \beta_{0}^{T}
$$

and thus $A_{0}^{-1}$ is required to be nonnegative. As before, we conclude from the fact that both $A_{0}$ and $A_{0}^{-1}$ are nonnegative that

$$
A_{0}=P_{\pi_{0}}\left(\tau_{0}\right) . \quad \pi_{0} \in \mathscr{S}_{n-1}, \tau_{0}>0
$$

(with $\tau_{0}$ a 1 by $n-1$ vector).

Let $\pi \epsilon \mathscr{S}_{n}$ be such that $\pi(i)=\pi_{0}(i)$ for $i=1,2, \ldots$, $n-1$ and $\pi(n)=n$. Then we can write $A$ as

$$
A=P_{\pi}(\tau)+\beta^{T} \epsilon_{0} \quad \pi \epsilon \mathscr{S}_{n}, \tau=\left(\tau_{0}, t_{n}\right)>0
$$

with $\beta=\left(b_{1} b_{2} \ldots b_{n}\right)$ and $\epsilon_{0}=\left(\begin{array}{lll}0 & 0\end{array} \ldots .01\right)$; i.e.,

$$
\beta^{T} \epsilon_{0}=\left(\begin{array}{ll}
0 & \beta^{T}
\end{array}\right) .
$$

The only further restriction is that the element $d$ in the lower right-hand corner be nonzero so that $A$ will be nonsingular. Clearly

$$
d=t_{n}+b_{n}
$$

so we require that $b_{n} \neq-t_{n}$. Since $b_{n}=\epsilon_{0} \beta^{T}$ this can be written

$$
\epsilon_{0} \beta^{T} \neq-t_{n}
$$

Now we return to (3) and conclude that the elements of $M(V)$ are exactly those of the form $K^{-1} A K$ restricted by (5). We note that

Let

$$
\epsilon_{0} K=\epsilon \text {. }
$$

$$
\gamma^{T}=K^{-1} \beta^{T}
$$

whence

$$
\epsilon_{0} \beta^{T}=\epsilon_{0} K \gamma^{T}=\epsilon \gamma^{T}
$$

and our restriction for nonsingularity becomes

$$
\epsilon \gamma^{T} \neq-t_{n} .
$$

This completes the proof of Theorem 1 .

Now let $f^{\prime}$ be the mapping of $M(V)$ onto $\mathscr{S}_{n-1}$ defined by

$$
f^{\prime}\left(K^{-1} P_{\pi}(\tau) K+\gamma^{T} \epsilon\right)=\{\lambda(\pi)\}^{-1}
$$

where $\lambda(\pi)(i)=\pi(i)$ for $i=1,2, \ldots, n-1$. This is well-defined, and is a homomorphism because $\lambda\left(\pi_{2} \pi_{1}\right)$ $=\lambda\left(\pi_{2}\right) \lambda\left(\pi_{1}\right)$ when $\pi_{1}(n)=\pi_{2}(n)=n$,

$$
\begin{aligned}
\left(K^{-1} P_{\pi_{1}}(\tau) K+\gamma_{1}^{T} \epsilon\right)\left(K^{-1} P_{\pi_{2}}(\sigma) K+\right. & \left.\gamma_{2}^{T} \epsilon\right) \\
& =K^{-1} P_{\pi_{2} \pi}(\rho) K+\gamma^{T} \epsilon
\end{aligned}
$$

(with $\rho$ as before), and

$$
\gamma^{T}=K^{-1} P_{\pi_{1}}(\tau) K \gamma_{2}^{T}+\left\{\epsilon \gamma_{2}^{T}+\epsilon K^{-1} \sigma^{T}\right\} \gamma_{1}^{T} .
$$

(Note that $\epsilon \gamma^{T}-r_{n}=\left(\epsilon \gamma_{1}^{T}-t_{n}\right)\left(\epsilon \gamma_{2}^{T}-s_{n}\right)$.)

As before it is easy to show that the kernel of $f^{\prime}$ is $N$ whence $M(V) / N \cong \mathscr{S}_{n-1}$, and Theorem 2 is proved.

The method of proof shows that similar results hold for

$$
M(S L)=L^{-1} M(S) L, M\left(S^{*} L\right)=L^{-1} M\left(S^{*}\right) L
$$

with $L$ any nonsingular matrix. Likewise, the results for $S^{*}$ can be extended to the set of vectors whose first $k$ entries are nonnegative.

(Paper 70B-179) 


\section{Publications of the National Bureau of Standards*}

\section{Selected Abstracts}

The solution to a nonlinear Lamm equation in the Faxén approximation, I. H. Billick and G. H. Weiss, J. Res. NBS 70A, No. 1 (Jan.-Feb. 1966), 75 cents.

An exact solution in the Faxén approximation is given for the Lamm equation in which the sedimentation coefficient is related to concentration as $s=s_{0}(\mathrm{l}-\mathrm{kc})$. It is shown that the solution in this case can be expressed in terms of the solution to the linear case $(k=0)$ with a modified argument. The boundary sharpening phenomenon expresses itself very clearly in the solution presented here.

A bounded automorphic form of dimension zero is constant, M. I. Knopp, J. Lehner, and M. Newman, Duke Math. J. 32, No. 3, 457-460 (Sept. 1965).

It is proved that a bounded automorphic form of dimension zero is constant. It is shown that this implies the known result that an abelian integral of the first kind on a compact Riemann surface cannot have all real periods. Finally, a simple proof is given of the result that a bounded automorphic function is constant.

Density distribution of polymer segments in the vicinity of an absorbing interface, C. A. J. Hoeve, J. Chem. Phys. 43, No. 9 , 3000-3008 (Nov. 1, 1965).

At a small distance from the interface corresponding to the effective thickness of the segments, the density drops suddenly by an amount that is the greater, the stiffer the chain. Beyond this distance the density is exponential in the distance from the interface for long chains and relatively weak adsorption.

Elastic stress-strain relations in perfect elastic fluids, $B$. Bernstein, E. Kearsley, and L. Zapas, Trans. Soc. Rheol. 9, Pt. 1, 27-39 (1965).

The theory of perfect elastic fluids deals with the non-equilibrium thermodynamics of finite viscoelastic deformation. The thermody. namics of finite elastic strain and of perfect elastic fluids are discussed. It is shown that the stress-strain relations for perfect elastic fluids may be written in a way which appears formally identical to those in élasticity theory, but the form of this dependence depends on past history.

Error bounds for asymptotic solutions of second-order difderential equations having an irregular singularity of arbitrary rank, F. W. J. Olver and F. Stenger, J. SIAM, Ser. B. 2, No. 2, 244-249 (1965).

Strict error bounds are established for the well-known asymptotic expansions of solutions of the differential equation

$$
\frac{d^{2} w}{d z^{2}}+f(z) \frac{d w}{d z}+g(z) w=0
$$

for large values of $z$, real or complex, where

$$
f(z) \sim z^{k} \sum_{s=0}^{\infty} \frac{f_{s}}{z^{s}}, \quad g(z) \sim z^{2 k} \sum_{s=0}^{\infty} \frac{g_{s}}{z^{s}}
$$

$k$ being an arbitrary non-negative integer, and $f_{s}, g_{s}$ constants.

Estimation of the parameters of the Hyper-Poisson distribution, E. L. Crow and G. E. Bardwell (Proc. Symp. Classical and Contagious Discrete Distribution, Montreal, Canada, Aug. 15-20, 1963), ch. V, pp. 127-140 (Statistical Publ. Soc., Calcutta, India, 1965).

The hyper-Poisson family of discrete distributions, a two-parameter generalization of the Poisson distributions, was introduced recently by the authors (Journal of the American Statistical Association, 59, March 1964). In this paper six different pairs of estimators (includ- ing four proposed in the previous paper) for the two parameters are presented and discussed: maximum likelihood, two moments, three moments, two moments plus zeroth frequency, mean plus first two frequencies, and two frequencies only. Three of these pairs are given by simple explicit formulas. Asymptotic variances are obtained for the three-moment estimators, and empirical variances for the three pairs of explicit estimators. Some of the estimators are applied to five examples of experimental or survey data.

Generalized functions of symmetric matrices, M. Marcus and M. Newman, Proc. Am. Math. Soc. 16, No. 4, 826-830 (Aug. 1965). Among other results, the following is proved: Let $A$ be a symmetric matrix with positive entries. Then a diagonal matrix $D$ exists having positive diagonal elements such that the matrix $D A D$ is doubly stochastic.

Inequalities for permanents and permanental minors, R. A. Brualdi and M. Newman, Proc. Camb. Phil. Soc. 61, 74I-746 (Jan. 1966).

The principal result of this paper is that for all non-negative doublystochastic matrices $A$ and all $\alpha$ such that $0 \leqslant \alpha \leqslant 1, \operatorname{per}(\alpha I+(1-\alpha) A)$ $\leqslant \alpha+(1-\alpha) \operatorname{per}(A)$, where $\operatorname{per}(A)$ denotes the permanent of $A$.

Normal subgroups of the modular group which are not congruence subgroups, M. Newman, Proc. Am. Math. Soc. 16, No. 4, 831-832 (Aug. 1965).

A new family of normal subgroups of finite index in the modular group which are not congruence subgroups, is given.

On the asymptotic solutions of second-order differential equations having an irregular singularity of rank one, with an application to Whittaker functions, F. W. J. Olver, J. SIAM, Ser. B. 2, No. 2, 225-243 (1965).

Strict error bounds are established for the well-known asymptotic expansions of solutions of the differential equation

$$
\frac{d^{2} w}{\overline{d z^{2}}}+f(z) \frac{d \dot{w}}{\dot{d} z}+g(z) w=0
$$

for large values of $z$, real or complex, where

$$
f(z) \sim \sum_{s=0}^{\infty} \frac{f_{s}}{z^{s}}, \quad g(z) \sim \sum_{s=0}^{\infty} \frac{g_{s}}{z^{s}}
$$

and $f_{s}, g_{s}$ are constants.

Real two-dimensional representations of the modular group and related groups, J. Lehner and M. Newman, Am. J. Math. 87, No. 4, 945-954 (Oct. 1965).

The principal result proved is the following: Put $T=\left(\begin{array}{rr}0 & 1 \\ -1 & 0\end{array}\right)$, $R_{\rho}=\left(\begin{array}{cr}0 & -\rho \\ 1 / \rho & 1\end{array}\right), G_{\rho}=\left\{T, R_{\rho}\right\}$ where $\rho \geqslant 1$. Then (i) $G_{\rho}$ is the free product of a cyclic group of order 2 and a cyclic group of order 3 , (ii) $G_{\rho}$ is a discrete group, (iii) every discrete faithful representation of the modular group $\Gamma$ by real $2 \times 2$ matrices is conjugate to $G_{\rho}$ for some $\rho \geqslant 1$, and (iv) $G_{\rho}$ and $G_{r}$ are conjugate for $\rho, \sigma \geqslant 1$ if and only if $\rho=\sigma$.

The fundamental solution and Huygen's principle for decomposable differential operators, J. E. Lagnese, Archive Rat. Mech. Anal. 19, No. 4, 299-307 (Jan. 22, 1965).

A nonparabolic linear partial differential operator $L$ of second order is called decomposable if there is a coordinate system in the Riemann 
space (the metric of which is defined by the coefficients of terms of second order) in which $L$ has the form $L=\mathscr{L}+\overline{\mathscr{L}}$ and such that the same independent variable does not appear in both $\mathscr{L}$ and $\mathscr{L}$. This paper is concerned with such operators and the principle result is an identity which relates in a rather simple manner the coefficients of the fundamental solutions (in the sense of Hadamard and Courant) of the three operators $\mathscr{L}, \mathscr{L}$, and $L$. The form of the identity shows that if both $\mathscr{L}$ and $\mathscr{L}$ have terminating fundamental solutions, the same must be true of $L$ and, consequently, in the case when $L$ is strictly hyperbolic, one may draw certain conclusions concerning the validity of Huygens' principle for $L$.

Similar resluts are obtained in the case when $L$ decomposes according to $L=\sum_{k=1}^{K} \mathscr{L}_{k}$. Two illustrative examples are given.

Atomic lifetimes in neon I, J. Z. Klose, Phys. Rev. 141, No. 1, 181-188 (Jan. 7, 1966).

Mean lives of a number of electronically excited atomic levels in $\mathrm{Ne}$ I have been determined using a method of delayed coincidence. Following a detailed description of the experimental procedure and a discussion of a series of trial runs in $\mathrm{He} \mathrm{I}$, the measured values of the mean lives of the $2 p_{1}$ through $2 p_{9}, 3 p_{1}, 3 p_{10}$, and $4 d_{1}^{\prime}$ (Paschen notation) levels in neutral neon are given. These lifetimes, determined from transitions with associated wavelengths extending from $\approx 3400$ to $\approx 6400 \AA$, ranged in value from $\approx 14$ to $\approx 500$ nsec. The lifetimes were estimated to contain possible systematic errors varying from 5 to $20 \%$ and are presented in comparison with corresponding results of other workers.

Generalized master equation for arbitrary initial states, J. Weinstock, Phys. Rev. 140, No. 1A, A98-99 (Oct. 4, 1965).

Exact generalized master equations, for both quantum and classical systems, are derived for completely arbitrary initial states (arbitrary initial "correlations") in the form of a density expansion. This result is a generalization of a previous equation which was restricted to initially "uncorrelated" states.

Generalized variational principles for electromagnetic junctions. Vibrations: application to the theory of waveguide, Proc. Symp. Electromagnetic Theory and Antennas, Copenhagen, Denmark, June 1962, ed. E. C. Jordan, pp. 253-260 (Pergamon Press Inc., New York, N.Y., 1963).

Generalized variational principles are stated for the elements-and for the associated electromagnetic fields - of the immittance matrices of waveguide junctions. The formulation applies to junctions containing arbitrary dissipative and anisotropic media, for which the underlying differential equations are not self-adjoint; and, by the use of bilinear (rather than quadratic) functional forms, permits direct treatment of off-diagonal elements of the immittance matrices.

AXLE: An axiomatic language for string transformations, K. Cohen and J. H. Wegstein, Commun. Assoc. Compt. Mach 8, No. 11, 657-661 (Nov. 1965).

AXLE is a language designed for data manipulation. Data arranged in a linear form in a workspace is transformed according to a table of axioms, called imperatives. A transformation consists of a matching procedure, which decides where an imperative is applicable, and a replacement procedure that modifies that part of the workspace. Imperatives are applied in accordance with definitions of symbolic terms, presented systematically in an assertion table. The process of definition includes the special case of recursive assertions. Several complete programs of imperatives are given to show a few applications of the language.

Morphological classification in the National Bureau of Standards mechanical translation system, L. F. Meyer, $J$. Assoc. Compt. Mach. 12, No. 4, 437-472 (Oct. 1965).

In linguistic work, morphology is the study of the rules by which words undergo changes in form. Morphological classification is the systematic organization of these rules. A detailed account of the morphological classification for Russian is given as used in the National Bureau of Standards project on the mechanical translation of Russian into English. The account includes the heuristic reasoning from which the classification system evolved, as well as complete classification tables, a description of the method of their construction, and some examples of their use.
Error bounds for asymptotic expansions of special functions in the complex plane, F. W. J. Olver, Proc. Symp. on Error in Digital Computation, U.S. Army Research Center, Madison, Wisconsin, April 26-28, 1965, Vol. 2, pp. 55-75 (John Wiley \& Sons, Inc., New York, N. Y., 1965).

Error bounds are given for a number of different types of asymptotic expansion derived from (i) the solution of ordinary linear differential equations of the second order, (ii) infinite integrals. Similarities between the results are discussed, and applications to the special functions of mathematical physics indicated.

Much of the paper is in the nature of a survey, but new results are given for asymptotic solutions, with respect to a parameter, in a region containing a regular singularity of the differential equation, and also for the asymptotic expansion of a simple integral of Laplace type.

New approach to the theory of fluctuations in a plasma, J. Weinstock, Phys. Rev. 139, No. 2A, A388-A393 (July 19, 1965). A rigorous but simple method is presented for calculating autocorrelation functions (fluctuations) of nonequilibrium plasmas including inhomogeneous and nonstationary plasmas-in external fields. This method is based upon the derivation of an exact and remarkably simple formal relation between autocorrelation functions and the usual one-particle distribution function $f_{1}(\mathbf{R}, \mathbf{v}, t)$ for an explicitly defined initial value. This relation explicitly reduces the problem of calculating fluctuation spectra to the problem of solving the usual kinetic equations for $f_{1}(\mathbf{R}, \mathbf{v}, t)$. Consequently, the central quantity of fluctuation theory is one and the same with the central quantity of kinetic theory, and the two theories are completely and explicitly united. To first order in the plasma parameter it is shown that one need only solve the linearized Vlasov equation for $f_{1}(\mathbf{R}, \mathbf{v}, t)$, and when this solution is substituted into our formal relation we obtain a general formula for autocorrelation functions which is valid for nonstationary systems and includes the effects of the transverse motion of the plasma in addition to the longutudinal motion. For stationary systems this formula approaches the numerous calculations of previous authors in the limits where the transverse terms vanish. As a result of the transverse terms, the spectrum of scattered light can have resonant peaks at frequencies which correspond to transverse modes of oscillation as well as to the well-known longitudinal modes.

Theory of relaxation in a group of weakly coupled systems, R. L. Peterson, Phys. Rev. 139; No. 4A, A1151-A1155 (Aug. 1965). A general formalism for computing relaxation times characterizing two or more weakly coupled macroscopic systems is presented. The physical nature of the systems is arbitrary, although applications to spin systems are briefly discussed. The main assumptions are that each system is internally in equilibrium with a well-defined temperature, that the systems are weakly coupled to one another, and that the Hamiltonians of the systems form a commuting set. No high-temperature approximations are used. The formalism is presented in an effort to unify in part the approaches which have been developed for many special physical situations, and to show the form some relaxation times take when the high-temperature approximations are not used. It is shown that when one of two coupled systems is a "Zeeman" system, the (spin) relaxation time is proportional to the magnetic adiabatic susceptibility.

On radiation of electromagnetic and electroacoustic waves in a plasma, J. R. Wait, Appl. Sci. Res. 11, Sec. B., 423-432 (June 11. 1965).

Radiation from current distributions in lossless compressible plasma media is considered. A linearized theory is used such that the isotropic electron plasma is regarded as a single fluid continuum. It is found that a considerable portion of the power is radiated as an electroacoustic-type wave. Some specialized results of other investigators are recovered.

\section{Other NBS Publications}

J.Res. NBS 70A, (Phys. and Chem.), No. 1, (Jan.-Feb. 1966), $\$ 1.00$.

Optical and magnetic spectra of bis- $N$-propylsalicylaldiminato copper (II). C. W. Reimann, G. F. Kokoszka, and H. C. Allen, Jr. Phase equilibria in the system niobium pentoxide-germanium dioxide. E. M. Levin. 
Phase equilibria in the system niobium pentoxide-boric oxide. E. M. Levin.

The solution to a nonlinear Lamm equation in the Faxén approximation. I. H. Billick and G. H. Weiss. (See above abstracts.)

A line formula notation system for coordination compounds: III Deviations from idealized configurations. E. Silverton and R. F. Pasternack.

The spherulitic crystallization of isotactic polypropylene from solution: On the evolution of monoclinic spherulites from dendritic chain-folded crystal precursors. F. Khoury.

Wavelengths, intensities, and Zeeman patterns in ytterbium spectra (Yb I, II, III, IV). W. F. Meggers and C. H. Corliss.

\section{J. Res. NBS 70A (Phys. and Chem.), No. 2 (Mar.-Apr. 1966), $\$ 1.00$.}

Mechanism of the depolymerization of polytetrafluoroethylene with pyrolytic and radiolytic initiation. "Roland E. Florin, M. S. Parker, and L. A. Wall.

Effect of some halogenated hydrocarbons on the flame speed of methane. C. Halpern.

Rupture-disk ampoule for anhydrous addition of hydrogen fluoride. A. R. Glasgow, Jr.

Further studies in the annealing of a borosilicate glass. S. Spinner and A. Napolitano.

Infrared spectra of the hydrated borates. C. E. Weir.

Interpretation of the solution absorption spectra of the $\left(\mathrm{PuO}_{2}\right) \dagger \dagger$ and $\left(\mathrm{NpO}_{2}\right) \dagger$ ions. J. C. Eisenstein and M. H. L. Pryce.

Vapor pressure and heat of sublimation of rhenium. E. R. Plante and R. Szwarc.

Steady-state response of silicon radiation detectors of the diffused $p-n$ junction type to $\mathrm{x}$ rays. II: Photodiode mode of operation. K. Scharf and J. H. Sparrow.

Absolute isotopic abundance ratios and the atomic weight of a reference sample of chromium. W. R. Shields, T. J. Murphy, E. J. Catanzaro, and E. L. Garner.

\section{J. Res. NBS 70C (Engr. and Instr.), No. 1 (Jan.-Mar. 1966),} 75 cents.

Coulometric calibration of microvolumetric apparatus. G. Marinenko and J. K. Taylor.

Effect of temperature and notch geometry on the tensile behavior of a titanium alloy. W. D. Jenkins and W. A. Willard.

Measurement standards for low and medium peak pulse voltages. A. R. Ondrejka and P. A. Hudson.

Temperature coefficient of $\mathrm{rf}$ permeability measurement using an impedance bridge as an equality indicating device. A. L. Rasmussen.

A test apparatus for the study of forced air-mixing devices. T. K. Faison, J. C. Davis, and P. R. Achenbach.

A table of radiation characteristics for uniformly spaced optimum endfire arrays with equal sidelobes, M. T. Ma and D. C. Hyovalti, NBS Mono. 95, (Dec. 10, 1965), 45 cents.

Safety rules for the installation and maintenance of electric supply and communication lines, Supplement 1 to NBS Handbook 81 (Dec. 15, 1965).

Calibration and test services of the National Bureau of Standards, NBS Misc. Publ. 250, 1965 edition (Oct. 28, 1965). \$1.00. Supersedes 1963 edition.

Standard Reference Materials: Methods for the chemical analysis of NBS copper-base spectrochemical standards, R. K. Bell, NBS Misc. Publ. 260-7 (Oct. 25, 1965), 60 cents

Standard Reference Materials: Analysis of uranium concentrates at the National Bureau of Standards, M. S. Richmond, NBS Misc, Publ. 260-8, (Dec. 1, 1965), 55 cents.

Standard Reference Materials: Half lives of materials used in the preparation of standard reference materials of nineteen radioactive nuclides issued by the National Bureau of Standards, S. C. Anspach, L. M. Cavallo, S. B. Garfinkel, J. M. R. Hutchinson, and C. N. Smith, NBS Misc. Publ. 260-9 (Nov. 15, 1965), 15 cents. Standard Reference Materials: Homogeneity characterization of NBS spectrometric standard II: Cartridge brass and low-alloy steel, H. Yakowitz, D. L. Vieth, K. F. J. Heinrich, and R. E. Michaelis, NBS Misc. Publ. 260-10, (Dec. 14, 1965). 30 cents.
Automotive lifts, CS142-65 (Sept. 1, 1965), 10 cents. Supersedes CS142-62.

Acrylonitrile-butadiene-styrene (ABS) plastic drain, waste, and vent pipe and fittings, CS270-65 (Apr. 1, 1965). 15 cents.

Polyvinyl chloride (PVC) plastic drain, waste, and vent pipe and fittings, CS272-65 (Apr. 1, 1965). 15 cents.

Standard stock sizes of machined tool steel bars (flast and squares), SPR267-65 (Aug. 15, 1965). 10 cents.

Accuracy in electrical and radio measurements and calibrations, 1965, ed. R. C. Powell, NBS Tech. Note 262-A (June 15, 1965), 50 cents.

Voltage ratio detector for millivolt signals, J. R. Houghton, NBS Tech. Note 266 (Dec. 13, 1965), 15 cents.

Organic chemistry: Radioactive carbohydrates, sugars in solution, aldol condensations, molecular structure, synthesis of selected compounds, air pollution studies, reference materials (organic), July 1964 to June 1965, ed. H. S. Isbell, NBS Tech. Note 274 (Dec. $3,1965), 60$ cents.

Radiochemical analysis: Activation analysis, instrumentation, radiation techniques, and radioisotope techniques, July 1964 to June 1965 , ed. J. R. DeVoe, NBS Tech. Note 276 (Jan. 7, 1966), \$1.00.

Flux averaging devices for the infrared, S. T. Dunn, NBS Tech. Note 279 (Dec. 9, 1965), 30 cents.

A peak ac-dc voltage comparator for use in a standards laboratory, L. A. Marzetta, NBS Tech. Note 280 (Jan. 17, 1966), 25 cents.

Materials for PLACEBO V, W. C. Watt, NBS Tech. Note 281 (Jan. 17, 1966), 50 cents.

Keypunch controls for string-punching of statistical data, M. J. Brennan, NBS Tech. Note 282 (Feb. 11, 1966), 25 cents.

A method for obtaining the parameters of electron-density profiles from topside ionograms, R. S. Lawrence and M. Hallenbeck, NBS Tech. Note 315 (Aug. 3, 1965), 25 cents.

Numerical simulation of ionospheric wave interaction experiments, T. M. Georges, NBS Tech. Note 325 (Oct. 25, 1965), 30 cents.

Adhesive bonding of various materials to hard tooth tissues. II Bonding to dentin promoted by a surface-active comonomer, R. L. Bowen, J. Dental Res. 44, No. 5, 895-902 (Sept.-Oct. 1965)

Adhesive bonding of various materials to hard tooth tissues. III. Bonding to dentin improved by pretreatment and the use of surface-active comonomer, R. L. Bowen, J. Dental Res. 44, No. 5, 903-905 (Sept.-Oct. 1965).

Adhesive bonding of various materials to hard tooth tissues. IV. Bonding to dentin, enamel, and fluorapatite improved by the use of a surface-active comonomer, R. L. Bowen, J. Dental Res. 44, No. 5, 906-911 (Sept.-Oct. 1965).

Approach to simple exponential decay in vibrational relaxation, T. Carrington, J. Chem. Phys. 43, No. 2, 473-479 (July 15, 1965).

Experimental atomic scattering factors for magnesium oxide, G. Burley, J. Phys. Chem. Solids 26, 1605-1613 (Apr. 8, 1965).

Major revisions made in new dry cell standard W. J. Hamer, Mag. Std. 36, No. 10, 306-308 (Oct. 1965).

Phase equilibria in the system aluminum oxide-tungsten oxide, J. L. Waring, J. Am. Ceram. Soc. 48, No. 9, 493-494 (Sept. 1965).

Relative signs of nuclear spin couplings in ${ }^{1} \mathrm{H}^{11} \mathrm{~B}^{19} \mathrm{~F}_{2}, \mathrm{E}$. B. Whipple, T. H. Brown, T. C. Farrar, and T. D. Coyle, J. Chem. Phys. 43, No. 5, 1841-1842 (Sept. 1, 1965).

The crystal structure of barium tetraborate, $\mathrm{BaO} \cdot 2 \mathrm{~B}_{2} \mathrm{O}_{3}, \mathrm{~S}$. Block and A. Perloff, Acta Cryst. 19, Pt. 3, 297-300 (Sept. 1965).

The system $\mathrm{WO}_{3}-\mathrm{B}_{2} \mathrm{O}_{3}$, E. M. Levin, J. Am. Ceram. Soc. 48, No. 9, 491-492 (Sept. 1965).

Vibrational fundamentals of $\mathrm{CF}_{2} \mathrm{~N}_{2}$ from the ultraviolet absorption spectrum, J. D. Simmons, I. R. Bartky, and A. M. Bass, J. Mol. Spectr. 17, No. 1, 48-49 (July 1965).

A precision noise-comparator, M. G. Arthur, C. M. Allred, and M. K. Cannon, IEEE Trans. Instr. Meas. IM-13, No. 4, 301-305 (Dec. 1964).

A variable characteristic impedance coaxial line, J. E. Cruz and R. L. Brooke, IEEE Trans. Micro. Theory Tech. MTT-13, No. 4, 477-478 (July 1965)

Impact of new technology on the forest industries, R. W. Smith, Jr., Proc. 2d Annual Forest Industries Marketing Conference, June 16-17, 1965, pp. 119-130 (University of Oregon Press, Eugene, Oregon, June 16, 1965).

Study of methods for estimating loudness, E. L. R. Corliss and G. E. Winzer, J. Acoust. Soc. Am. 38, No. 3, 424-428 (Sept. 1965). Acoustical thermometer, H. H. Plumb and G. Cataland, Science 150, No. 3693, 155-161 (Oct. 8, 1965). 
An international comparision of inductive voltage divider calibra tions at 400 to $1000^{\circ} \mathrm{Hz}$, W. C. Sze, A. F. Dunn, and T. L. Zapf IEEE Trans. Instr. Meas. IM-14, No. 3, 124-131 (Sept. 1965)

Precise voltage-ratio measurement, T. L. Zapf, Electro-Technol. 76, No. 4, 95-102 (Oct. 1965).

An image source technique for calculating reflection of gamma rays or neutrons, C. Eisenhauer, Health Phys. 11, 1145-1154 (1965).

Angular scattering law for the moon at 6-meter wavelength, W. K. Klemperer, J. Geophys. Res. Letters 70, No. 15, 3798-3800 (Aug. 1, 1965).

Dissociation of $\mathrm{H}_{2}+$ by electron impact, G. H. Dunn, B. Van Zyl, and R. H. Zare, Phys. Rev. Letters 15, No. 15, 610 (Oct. 11, 1965).

Effects of tropospheric refraction in earth-space links, K. A. Norton, Book, Progress in Radio Science 1960-1963-Radio and Troposphere, ed. F. du Castel, II, pp. 186-210 (Elsevier Publ. Co., Amsterdam, The Netherlands, 1965).

Fermi resonance in condensed $\mathrm{CF}_{4}$ and $\mathrm{CCl}_{4}, \mathrm{~S}$. Abramowitz and J. J. Comeford, Spectrochim. Acta 21, 1479-1486 (1965).

Field desorption of thorium from a field-evaporated tungsten surface, R. D. Young, J. Appl. Phys. 36, No. 9, 2656-2657 (Sept. 1965).

Laboratory measurement of the rate of the reaction $\mathrm{N}_{2}+\mathrm{O}-\mathrm{NO}+\mathrm{N}$ at thermal energy, E. E. Ferguson, F. C. Fehsenfeld, P. D. Goldan, A. L. Schmeltekopf, and H. I. Schiff, Planet. Space Sci. 13, 823-827 (1965).

Long-period very low frequency emission pulsations, W. B. Carson, J. A. Koch, J. H. Pope, and R. M. Gallet, J. Geophys. Res. 70, No. 17, 4293-4303 (Sept. 1, 1965).

Meson and baryon resonances in relativistic $\mathrm{SU}(6), H$. Harari, D. Horn, M. Kugler, H. J. Lipkin, and S. Meshkov, Phys. Rev. 140, No. 2B, B431-B433 (Oct. 25, 1965).

Positive ion-neutral reactions in the ionosphere, E. E. Ferguson, F. C. Fehsenfeld, P. D. Goldan, and A. L. Schmeltekopf. J. Geophys. Res. 70, No. 17, 4324-4329 (Sept. 1, 1965).

Potential-energy curves for $\mathrm{CO}$ and $\mathrm{CO}^{+}, \mathrm{P}$. H. Krupenie and S. Weissman, J. Chem. Phys. 43, No. 5, 1529-1534 (Sept. 1, 1965).

Rotating shutter for time-resolved spectroscopy in the microsecond range, I. R. Bartky and A. M. Bass, Appl. Opt. 4, No. 10, 13541356 (Oct. 1965).

Solar-flare frequency and observing-time patterns, C. S. Warwick, Astrophys. J. 142, No. 2, 767-772 (Aug. 15, 1965).

Solution polishing of oriented single crystals, R. D. Deslattes, B. G. Simson, and A. T. Horton, Rev. Sci. Instr. 36, No. 7, 943-944 (July 1965).

Spectrum of doubly ionized lanthanum (La III), J. Sugar and V. Kaufman, J. Opt. Soc. Am. 55, No. 10, 1283-1285 (Oct. 1965).

Speed of sound in fluid parahydrogen, B. A. Younglove, J. Acoust. Soc. Am. 38, No. 3, 433-438 (Sept. 1965).

Stress-strain relationships in yarns subjected to rapid impact loading. Part XI: Strain distributions resulting from rifle bullet impact, J. C. Smith, C. A. Fenstermaker, and P. J. Shouse, Textile Res. J. 35, No. 8, 743-757 (Oct. 21, 1965).

$\mathrm{SU}(6)_{\mathrm{W}}$ photoproduction and meson-baryon scattering amplitudes, J. C. Carter, J. J. Coyne, S. Meshkov, D. Horn, M. Kugler, and H. J. Lipkin, Phys. Rev. Letters 15, No. 8, 373-377 (Aug. 23, 1965).

An analysis of the effects of ground reflection in line-of-sight phase systems, M. C. Thompson, Jr. IEEE Trans. Ant. Prop. AP-13, No. 4, 564-567 (July 1965)

Conjugate observations of solar proton events: delayed ionospheric changes during twilight, H. J. A. Chivers, and J. K. Hargreaves, Planet. Space Sci. 13, 583-592 (1965).

Cosmic-noise survey at 65 degrees (N) declination in the $5-50 \mathrm{Mc} / \mathrm{s}$ band, R. Parthasarathy and G. M. Lerfald, Monthly Notices Roy. Astron. Soc. 129, No. 6, 395-409 (1965).

Dynamic spectral characteristics of micropulsation pearls, J. H. Pope, J. Geophys. Res. 70, No. 15, 3595-3603 (Aug. 1, 1965) On the determination of the electron density within discrete aurora forms in the $E$ region, R. D. Hunsucker, J. Geophys. Res. 70, No. 15, 3791-3792 (Aug. 1, 1965).

Some additional features of radar returns from the equatorial elec torjet, B. B. Balsley, J. Geophys. Res. 70, No. 13, 3175-3182 (July 1, 1965).

Chemical structures as information-representations, transformation, and calculations, S. J. Tauber, G. F. Fraction, and H. W Hayward, Book, Colloquium on Technical Preconditions for Retrieval Center Operations, Philadelphia, Pa., Apr. 24-25,
1964, ed. B. F. Cheydleur, pp. 73-101 (Spartan Books, Inc., Washington, D. C., 1965).

Determination of hide substance in leather by the Kjeldahl method, S. Dahl, Book, The Chemistry and Technology of Leather IV, ch. 52, 45-70 (Reinhold Publ. Corp., New York, N. Y., 1965).

Determination of tellurium by cathode-ray polarography, E. J. Maienthal and J. K. Taylor, Anal. Chem. 37, No. 12, 1516-1519 (Nov. 1965).

Digital handling of chemical structures and associated information, S. J. Tauber, Proc. 20th Natl. Conf. Association for Computing Machinery, pp. 206-216 (1965).

Electrodeposition of alloys, past, present, and future, A. Brenner, Plating 52, No. 12, 1249-1257 (Dec. 1965).

Physical and mechanical properties of electrode-deposited copper 1. Literature survey, V. A. Lamb and D. R. Valentine, Plating 52, No. 12, 1289-1311 (Dec. 1965).

Some experience with the Hayward linear notation system, H. W. Hayward, H. M. S. Sneed, J. H. Turnipseed, and S. J. Tauber, J. Chem. Doc. 5, No. 3, 183-189 (Aug. 1965).

The crystal and molecular structure of iodopentaborane-9, L. H. Hall, S. Block, and A. Perloff, Acta Cryst. 19, pt. 4, 658-661 (Oct. 1965).

The use of visible and ultraviolet spectroscopy to identify carbonyl compounds in photodegraded plastics, V. E. Grady and J. R. Wright, Polymer Engr. Sci. 5, No. 4, 284-290 (Oct. 1965).

A theoretical model for predicting thermal stratification and self pressurization of a fluid container, R. W. Arnett and D. R. Millhiser, Proc. Conf. Propellant Tank Pressurization and Stratification, Jan. 20-21, 1965, II, 1-16 (NASA, George C. Marshall Space Flight Center, Huntsville, Alabama, 1965).

Calibration of peak A-C to D-C comparators, D. Flach and L. A. Marzetta, (ISA 20th Annual Conference and Exhibit, Los Angeles, Calif., Oct. 4-7, 1965), IS A Preprint 14.2-3-65 (1965).

Cryogenics and space technology, R. B. Scott, Proc. XIth Intern. Congress of Refrigeration, Munich, Germany, 1963, pp. 105-114, (Pergamon Press Inc., New York, N. Y., 1965).

Evidence for an electrochemical-mechanical stress corrosion fracture in a stainless steel, H. L. Logan, M. J. McBee, and D. J. Kahan, Corrosion Sci. 5, 729-730 (1965).

Preparation of copper crystals with low electrical resistivity, J. J. Gniewek and A. F. Clark, J. Appl. Phys. 36, No. 10, 3358-3359 (Oct. 1965).

The world of cryogenics. III. Cryogenics at the National Bureau of Standards Boulder Laboratories, B. W. Birmingham, Cryogenics 5, No. 3, 121-128 (June 1965).

Cesium beam atomic time and frequency standards, R. E. Beehler, R. C. Mockler, and J. M. Richardson, Metrologia 1, No. 3, 114131 (July 1965).

International weights and measures, C. H. Page, (ISA 20th Annual Conference and Exhibit, Los Angeles, Calif., Oct. 4-7, 1965), IS A Preprint 33.3-1-65 (1965).

Measurement standards, A. G. McNish, Intern. Sci. Tech., 58-66 (Conover-Mast. Publ., New York, N. Y., Nov. 1965).

Of time and the atom, G. E. Hudson, Phys. Today 18, No. 8, 34-38 (Aug. 1965).

A new speculation of terrestrial helium loss, E. E. Ferguson, F. C. Fehsenfeld, and A. L. Schmeltekopf, Planet. Space Sci. 13, 925-928 (1965).

Breadth of decay quanta in gas lasers, J. A. White, J. Opt. Soc. Am. 55, No. 11, 1436-1442 (Nov. 1965).

Classical diagram technique for calculating thermostatic properties of Solids; application to dielectric susceptibility of paraelectrics, R. M. Wilcox, Phys. Rev. 139, No. 4A. A1281-Ai291 (Aug. $16,1965)$.

Conformation of polystyrene adsorbed at the $\theta$-temperature, $\mathrm{R}$. $\mathrm{R}$. Stromberg, D. J. Tutas, and E. Passaglia, J. Phys. Chem. 69, No. 11, 3955-3963 (Nov. 1965).

Critical-point phenomena, M. S. Green, Science 150, No. 3693, 229-236 (Oct. 8, 1965).

Density expansion of the viscosity of a moderately dense gas, J. V. Sengers, Phys. Rev. Letters 15, No. 12, 515-517 (Sept. 20, 1965).

Differences in the characteristic electron energy-loss spectra of solid and liquid bismuth, C. J. Powell, Phys. Rev. Letters 15, No. 22, 852-854 (Nov. 29, 1965).

Dipole moment of $\mathrm{PCl}_{4} \mathrm{~F}$ from the nonresonant microwave absorption of the vapor, A. A. Maryott and S. J. Kryder, J. Chem Phys. 43, No. 7, 2556-2557 (Oct. 1, 1965). 
Infrared and microwave spectra of CICN, W. J. Lafferty, D. R. Lide and R. A. Toth, J. Chem. Phys. 43, No. 6, 2063-2070 (Sept. 15,1965 ).

Investigation of the anomaly in the response of silicon semiconductor radiation detectors at low temperatures, W. R. Dodge, S. R. Domen, A. T. Hirshfeld, and D. D. Hoppes, IEEE Trans. Nuclear Sci. NS-12, No. 1, 295-303 (1965).

Ionization energies of the singly ionized rare earths, J. Sugar and J. Reader, J. Opt. Soc. Am. 55, No. 10, 1286-1290 (Oct. 1965).

Microwave spectrum and barrier to internal rotation in methylsilyl acetylene, W. H. Kirchhoff and D. R. Lide, Jr., J. Chem. Phys. 43, No. 7, 2203-2213 (Oct. 1, 1965).

Modes of propagation in a bounded compressible plasma, J. R. Wait, Electronics Letters 1, 193-194 (Sept. 1965).

Philosophical influences on radiation protection standards, L. S. Taylor, Health Phys. 11, 859-864 (1965).

Precision refractometry of small lens-shaped objects, J. R. MeyerArendt, Lab. Invest. 13, No. 5, 529-532 (1965).

Quantum statistics of fully ionized gases, W. T. Grandy and F. Mohling, Ann. Phys. 34, No. 3, 424-464 (Oct. 1965).

Resonance in the light scattered from a plasma, J. Weinstock, Physics Letters 18, No. 1, 21-22 (Aug. 1, 1965).

The direction of the force on a dislocation and the sign of the Burgers vector, R. DeWit, Acta Met. 13, No. 11, 1210-1211 (1965).

Ultrasonic determination of crystalline resonances and sound veloci ties, using NMR techniques, R. J. Mahler, and W. H. Tannttila, J. Acoust. Soc. Am. 38, No. 3, 429-432 (Sept. 1965).

Another method of synthesizing nonuniformly spaced arrays, M. T Ma, IEEE Trans. Ant. Prop. AP-13, No. 5, 833-834 (Sept. 1965)

On the relation between auroral radio absorption and very low frequency emissions, W. L. Ecklund, J. K. Hargreaves, and J. H. Pope, J. Geophys. Res. 70, No. 17, 4285-4292 (Sept. 1, 1965).

The effect of ion-drag on the neutral air in the ionospheric $F$-region, H. Rishbeth and L. R. Megill, Ann. Geophys. 21, No. 2, 235-244 (Apr.-June 1965)

Deuterium isotope effect in vacuum-ultraviolet absorption coefficients of water and methane, A. H. Laufer and J. R. McNesby, Can. J. Chem. 43, No. 12, 3487-3490 (Dec. 1965).

Electrochemical methods, J. K. Taylor, E. J. Maienthal, and G. Marinenko, Book, Trace Analysis: Physical Methods, ed. G. H. Morrison, ch. 10, pp. 377-433 (Interscience Publ. Inc., New York, N.Y., 1965).

Interaction of oxygen with platinum, A. J. Melmed, J. Appl Phys. 36, No. 11, 3691-3692 (Nov. 1965).

Proton transfer reactions occurring in the gas-phase radiolysis, P. Ausloos and S. G. Lias, Discussions Faraday Soc. 39, 36-44 (1964).

Restoration of complete dentures inadvertently warped by the patient: Report of case, J. B. Woelfel and G. C. Paffenbarger, J. Am. Dental Assoc. 71, 866-870 (Oct. 1965).

Solid-vapor equlilbrium in the system hydrogen-methane, M. J. Hiza and R. N. Herring (Proc. 1965 Cryogenic Engineering Conf., Philadelphia, Pa., Aug. 17-21, 1964), Book, International Advances in Cryogenic Engineering, ed. K. D. Timmerhaus, 10, Sec. Q, pp. 182 (Plenum Press Inc., New York, N.Y., 1965).

Spectrophotometric determination of bromine and hydrogen bromide, E. C. Creitz, Anal. Chem. 37, 1690-1692 (Dec. 1965).

Comment of obscurities of oscillator noise, L. Fey, W. R. Atkinson, and J. Newman, Proc. IEEE Letter 52, 104-105 (Jan. 1964).

Cryogenic fluid, two-phase critical flow studies related to reactor systems, R. V. Smith, H. S. Isbin, H. K. Fauske, M. Petrick, C. H. Robbins, and F. R. Zuludek, Proc. 3d United Nations Intern. Conf. Peaceful Uses of Atomic Energy, Geneva, Switzerland, Aug. 31-Sept. 9, 1964.

Field strength calibration techniques at the NBS, H. E. Taggart, IEEE Trans. Electromag. Compatability EC-7, No. 2, 163-169 (June 1965).

Field-strength measurements in a multipath field, C. C. Watterson, Proc. 4th Natl. IEEE Symp. Radio Frequency Interference, San Francisco, Calif., June 28-29, 1962.

Gearing errors as related to alignment techniques of the rotaryvane attenuator, W. Larson, 19th Annual IEEE Conference and Exhibit on Instrumentation and Measurements, New York, N. Y., Oct. 12-15, 1964, Preprint No. 12-5-2-64 (Sept. 1965); IEEE Instr. Meas. IM-14, No. 3, 117-123 (Sept. 1965).

Optical instrumentation for the biologist, J. R. Meyer-Arendt, Appl. Opt. 4, No. 1, 1-9 (Jan. 1965).
The NBS cryogenic data center, Proc. XI Intern. Congress Refrigeration, Munich, Germany, Aug. 28, 1963, pp. 110-114 (1965). Timing and space navigation with an existing ground based system, G. Hefley, R. F. Linfield, and R. H. Doherty, AGARD Navigation Systems for Aircraft and Space Vehicles, pp. 490-506 (Pergamon Press Inc., New York, N. Y., 1962).

22 ISCC-NBS centroid colors of maximum contrast, K. L. Kelly, Color Engr. 3, No. 6, 26-27 (Nov.-Dec. 1965).

A stable arc source of high ultraviolet radiance, C. R. Yokley, Proc. Symp. Solar Radiation Simulation, Los Angeles, Calif., Jan. 18-20, 1965, pp. 107-110 (1965).

A latitude survey of the night airglow, T. N. Davis and L. L. Smith, J. Geophys. Res. 70, No. 5, 1127-1138 (Mar. 1965).

A theoretical study of the Martian and Cyntherian ionospheres, R. B. Norton, Natl. Aeronautic. Space Admin. Tech. Note TN D-2333 (1964).

Atomic lifetimes in neon I, J. Z. Klose, Phys. Rev. 141, No. 1, 181-188 (Jan. 7, 1966).

Coherent Raman effect in the off-axis Raman resonator, D. A. Jennings and H. Takuma, Appl. Phys. Letters 4, No. 11, 185-186 (June 1964).

Comment on the "Difference between a non-LTE, and a pure absorption, model for the line-blanketing effect," R. N. Thomas, Astrophys. J. 141, No. 1, 333-335 (Jan. 1965).

Flare importance ratings-some hope for improvement, C. S. Warwick, Proc. Natl. Aeronautic Space Admin. Flare Conf. The Physics of Solar Flares, pp. 27-28 (1964).

Infrasonic observations of the May 16, 1964, volcanic explosion on the island of Bali, V. H. Goerke, J. M. Young, and R. K. Cook, J. Geophys. Res. 70, No. 24, 6017-6022 (Dec. 15, 1965).

Interaction of $350-\mathrm{keV}$ polarized neutrons with oriented ${ }^{465} \mathrm{Ho}$ nuclei, R. Wagner, P. D. Miller, T. Tamura, and H. Marshak, Phys. Rev. 139, No. 1B, B29-B46 (July 12, 1965).

Nonanalyticity of transport coefficients and the complete density expansion of momentum correlation functions, J. Weinstock, Phys. Rev. 140, No. 2A, A460-A465 (Oct. 18, 1965).

Non-linear ambipolar diffusion across a magnetic field, K. B. Persson and E. R. Mosburg, Phys. Fluids 7, No. 11, 1829-1833 (Nov. 1964).

Nuclear size determination by neutral-pion photoproduction, R. A. Schrack, Phys. Rev. 140, No. 4B, B987-B904 (Nov. 22, 1965).

On the use of thermopiles for absolute radiometry in the far ultraviolet, R. G. Johnston, and R. P. Madden, Appl. Opt. 4, No. 12, 1574-1580 (Dec. 1965).

Phonon induced nuclear dipole transitions, R. J. Mahler (Proc. XIIIth Colloque and Relaxation in Solids), Book, Nuclear Magnetic Resonance and Relaxation in Solids, ed. L. V. Gerven, pp. 202209 (North Holland Publ. Co., Amsterdam, The Netherlands, 1965).

Remarks on a paper by T. Makino "On the cosmic-ray cut-off rigidities and the earth's magnetic Field," H. H. Sauer, Report of Ionosphere and Space Research in Japan 19, No. 1, 54-55 (1965).

Solute nuclear magnetic resonances in primary lead alloys, L. H. Bennett, R. M. Cotts, and R. J. Snodgrass (Proc. XIIIth Colloque and Relaxation in Solids), Book, Nuclear Magnetic Resonance and Relaxation in Solids, ed. L. V. Gerven, pp. 171-180 (North-Holland Publ. Co., Amsterdam, The Netherlands, 1965).

Spectra of $\mathscr{C}_{2}$ in solidified gases at $4^{\circ}$ and $20^{\circ} \mathrm{K}, \dot{\mathrm{R}}$. L. Barger and H. P. Broida, J. Chem. Phys. 43, No. 7, 2371-2376 (Oct. 1, 1965).

Spectra of $\mathrm{C}_{3}$ in solidified gases at $4^{\circ}$ and $20^{\circ} \mathrm{K}$, R. L. Barger and H. P. Broida, J. Chem. Phys. 43, No. 7, 2364-2370 (Oct. 1, 1965). Spectrum of stationary homogeneous magnetohydrodynamic turbulence, C. M. Tchen, Phys. Fluid 8, No. 9, 1659-1667 (Sept. 1965). Suppression at high temperature of effects due to statistics in the second virial coefficient of a real gas, S. Y. Larsen, J. E. Kilpatrick, E. H. Keb, and H. F. Jordan, Phys. Rev. 140, No. 1A, Al29A130 (Oct. 1965).

The brush cathode plasma-a well behaved plasma, K. B. Persson, J. Appl. Phys. 36, No. 10, 3086 (Oct. 1965).

The realization and use of the international practical temperature scale of 1948, J. P. Evans, ISA 20th Annual Conference and Exhibit, Los Angeles, Calif., Oct. 4-7, 1965), ISA Preprint 14.31-65 (1965).

The relationship of a.c. resonant probes to resonant scattering, W. M. Leavens, Physics Letters 19, No. 2, 118-120 (Oct. 1, 1965). Thermal conductivity and viscosity of simple fluids, J. V. Sengers, Intern. J. Heat Mass Transfer 8, 1103-1116 (1965).

A study of auroral absorption events at the south pole: 2. Conjugate properties, J. K. Hargreaves and H. J. A. Chivers, J. Geophys. Res. 70, No. 5, 1093-1102 (Mar. 1965). 
Characteristic variations in the antarctic ionosphere, V. L. Peterson, G. Stonehocker, and J. W. Wright, Antarctic Research Series, Am. Geophys. Union, Geomagnetism and Aeronomy 4, 47-75 (1965).

International comparison on dielectric measurements, E. Rushton, G. Russell, B. W. Petley, H. E. Bussey, J. E. Gray, E. C. Bamberger, and D. Morris, IEEE Trans. Instru. Meas. IM-13, No. 4, 305-311 (Dec. 1964).

Interrelations of sporadic $\boldsymbol{E}$ and ionospheric currents, S. Matsushita, Book, Ionospheric Sporadic-E, ed. E. K. Smith and S. Matsushita, ch. II, pt. C, No. 5, 344-375 (Pergamon Press Inc., New York, N.Y., 1962).

Lightning characteristics as derived from sferics, W. L. Taylor (Proc. 3d Intern. Conf. Atmospheric and Space Electricity, Montreus, Switzerland, May 1963), Book, Problems of Atmospheric and Space Electricity, ed. S. C. Coroniti, pp. 388-404 (Elsevier Publ. Corp., Amsterdam, The Netherlands, 1965).

Long term characteristics for air-ground propagation in band nine, R. S. Kirby, IEEE Antenna propagation Intern. Symp. Digest, pp. 43-47 (July 9-11, 1963).

On the continuity equation for electron density in the ionosphere T. Shimazaki, J. Atmospheric Terrest. Phys. 27, 593-604 (1965).

Studies of Alouette observations at the CRPL, W. Calvert, H. Rishbeth, and T. Van Zandt, Trans. American Geophysical Union, IG Bull. 45, No. 2, 398-401 (June 1964).

Topside sounding as a tool for global ionosphere studies, R. W. Knecht, IEEE Trans. Ant. Prop. Programs Digest, pp. 21-23 (1963).

Gas phase radiolysis and vacuum ultraviolet photolysis of 2- and 3-pentanone, A. Scala and P. Ausloos, J. Phys. Chem. 70, No. 1, 260-269 (Jan. 1966).

New developments in dental materials: a world-wide survey, G. C. Paffenbarger, Intern. Dental J. 15, No. 3, 311-422 (Sept. 1965).

Quenching of the triplet state of acetone and biacetyl by various unsaturated hydrocarbons, R. E. Rebbert and P. Ausloos, J. Am. Chem. Soc. 87, No. 24, 5569-5572 (Dec. 20, 1965).

Vacuum-ultraviolet photolysis of ethane at high temperature. II Collisional deactivation of excited ethylene, R. F. Hampson, Jr., and J. R. McNesby, J. Chem. Phys. 43, No. 10, 3592-3596 (Nov. $15,1965)$.

Foreword, R. G. Scott, Book, Cryogenics, pp. V (Reinhold Publ. Corp., New York, N.Y., 1964).

MAGIC-A machine for automatic graphics interface to a computer, D. E. Rippy and D. C. Humphries, Proc. Fall Joint Computer Conf., Nov. 20-Dec. 2, 1965, Los Vegas, Nevada, pp. 819-830 (Spartan Books, Inc., Wash., D.C., 1965).

The NBS time scale and its relation to other time scales, J. A. Barnes and R. C. Mockler (Proc. XIV General Assembly of URSI, Tokyo, Japan, 1963), Book, Progress in Radio Science 1960-1963. Vol. I. Radio Standards and Measurements, ed. R. W. Beatty, p. 41 (Elsevier Pub. Co., Amsterdam, The Netherlands, 1965).

Annual report of the National Bureau of Standards, C. E. Moore, Astron. J. 70, No. 9, 637-639 (Nov. 1965).

Oxygen metastable atom production through photodetachment, L. M. Branscomb, S. J. Smith, and G. C. Tisone, J. Chem. Phys. 43, No. 8, 2906-2907 (Oct. 15, 1965).

The current revision of the solar spectrum table $\lambda 2935 \AA$ to $\lambda 8770 \AA$, C. E. Moore, Proc. Utrecht Symp. Solar Spectrum, Utrecht, The Netherland, Aug. 26-31, 1963, ed. C. DeJager, pp. 89-101 (D. Reidel Publ. Co., Dordrecht, The Netherlands, 1965).

Total cross section of $14 \mathrm{MeV}$ neutrons using aligned ${ }^{165} \mathrm{Ho}$ nuclei, H. Marshak, A. Richardson, and T. Tamura, Phys. Rev. Letters 16. No. 5, 194-197 (Jan. 31, 1966).

Influence or irregular terrain on propagation, J. W. Herbstreit (Proc. XIV General Assembly of URSI, Tokyo, Japan, 1963), Book, Progress in Radio Science 1960-1963. Vol. II. Radio and Troposphere, ed. F. du Castel, pp. 141-156 (Elsevier Publ. Co., Amsterdam, The Netherlands, 1965).

*Publications for which a price is indicated are available by purchase from the Superintendent of Documents, U.S. Government Printing Office, Washington, D.C., 20402 (foreign postage, onefourth additional). Reprints from outside journals and the NBS Journal of Research may often be obtained directly from the authors. 